\title{
Comparison of single-stage and two-stage thermophilic anaerobic digestion of SS-OFMSW during the start-up phase
}

\author{
S. Ghanimeh ${ }^{\mathrm{a}, \mathrm{b}}$, D. Al-Sanioura ${ }^{\mathrm{a}}$, P. E. Saikaly ${ }^{\mathrm{c}}$, M. El-Fadel ${ }^{\mathrm{a} \dagger}$ \\ ${ }^{a}$ Department of Civil \& Environmental Engineering, American University of Beirut, Lebanon \\ ${ }^{b}$ Department of Civil \& Environmental Engineering, Notre Dame University, Lebanon \\ ${ }^{c}$ Division of Biological and Environmental Sciences \& Engineering, KAUST, Kingdom of Saudi Arabia \\ ${ }^{\dagger}$ Corresponding Author: mfadel@aub.edu.lb
}

Abstract The accumulation of volatile fatty acids during the anaerobic digestion of biodegradable substrate such as Source Sorted Organic Fraction of Municipal Solid Waste (SS-OFMSW) is associated with an inhibitory effect on methane producing biochemical pathways. While inconclusive at times, the usage of two-stage digesters has been argued as a potential solution for this issue. In this study single-stage vs. two-stage thermophilic digesters, fed with SS-OFMSW, were examined during the startup phase while increasing the loading rate from 0.5 to $\sim 2$ g VS.L ${ }^{-1} \mathrm{~d}^{-1}$. While both systems exhibited a stable performance, with neutral $\mathrm{pH}$ and low intermediateto-partial alkalinity, the two-stage digester exhibited better effluent quality with 79 and $57 \%$ lower average total chemical oxygen demand (TCOD) and soluble COD (SCOD), respectively. Also, upon reaching steady-state conditions, the two-stage system showed a superior performance with an overall methane content of $54 \%$, compared to an average of $45 \%$ in the single-stage system.

\section{Graphical Abstract}

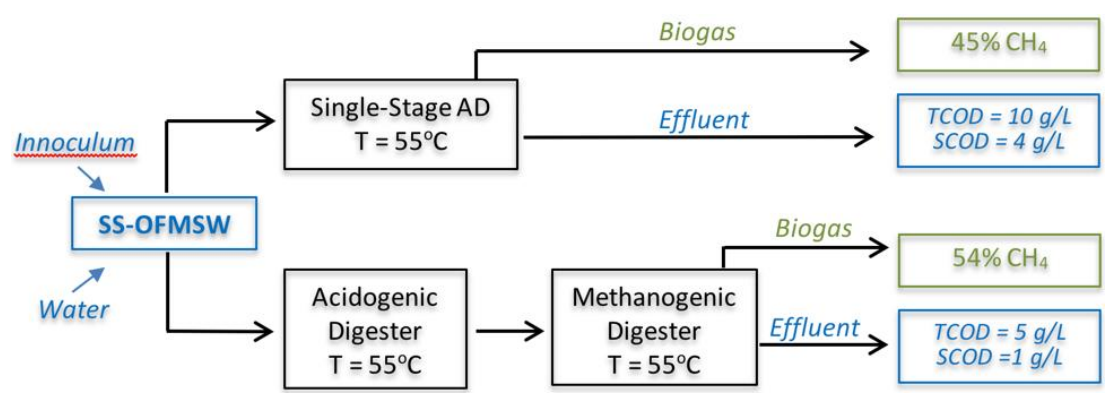

\section{Novelty Statement}

Despite a large body of literature addressing the benefits of two-stage anaerobic digestion, compared to conventional one-stage digestion, the results are inconclusive and even contradictory often because of differences in operating conditions and type of feed. Most studies comparing single- with two-stage digesters have been reported under mesophilic temperatures, mostly during steady-state operation. With the growing interest in maximizing energy generation from municipal solid waste, thermophilic applications become justifiable. Given the importance of the start-up phase in defining the future performance of a digester, this study compares onewith two-stage digestion of SS-OFMSW during startup, under thermophilic conditions.

Keywords Thermophilic anaerobic digestion; single-stage vs. two-stage; SS-OFMSW 


\section{Introduction}

33 The growing pressure towards effective disposal of the Organic Fraction of Municipal Solid Waste (OFMSW)

34 coupled with the rising interest in carbon neutral energy, has encouraged research on clean energy from biomass and organic waste. Source-Sorted OFMSW (SS-OFMSW), with its high moisture content and biodegradability, is a good candidate for anaerobic digestion (AD) offering the advantage of producing methane and soil conditioners $[1,37,38]$. However, with its low carbon-to-nitrogen $(\mathrm{C} / \mathrm{N})$ ratio, AD of OFMSW is associated with a low stability due to the accumulation of intermediate byproducts such as volatile fatty acids (VFA) [2]. This constraint is more pronounced under thermophilic temperatures $\left(50-55^{\circ} \mathrm{C}\right)$ due to faster kinetics compared to mesophilic systems $\left(30-40^{\circ} \mathrm{C}\right)$ leading to an even higher accumulation of VFA, especially with highly biodegradable wastes such as OFMSW [3].

The separation of the acidogenic and methanogenic phases of the AD process has been promoted in some studies to alleviate the accumulation of metabolites by buffering the loading rate and organic matter in the first stage allowing a healthier methanogenesis in the second stage $[4,5]$. As such the AD process is separated into two stages with the first stage encompassing the fermentative hydrolytic, the acidogenic and the acetogenic bacteria, while the methanogenic archaea can be separated in a second stage due to their lower resilience, tolerance to upsets, and growth rate [4]. The two-stage digesters can reportedly achieve higher methane generation and chemical oxygen demand (COD) removal [2, 6], lower VFA accumulation [7], improved functional stability for waste with poor cellulose such as OFMSW [8], better resistance to loading fluctuation and more tolerance of higher loading rates $[5,8,9]$, as well as reduced retention time requirements [10]. In contrast, other studies showed that a well-designed and adequately operated single-stage continuous stirred tank reactor (CSTR) can perform similar or better than two-stage systems [11, 12]. Furthermore, the separation of the hydrolysis/acidogenesis and methanogenesis phases (or increasing the distance between acidogens and methanogens) is argued to hamper the syntrophic associations and prevent the transfer of hydrogen between both groups of species, thus negatively affecting the synergy between the "producing" and "consuming" microorganisms and increasing the accumulation of propionate and butyrate, both being methanogenic inhibitors $[13,14,15,16]$. Also, it has been shown that one-stage system is preferable for the treatment of fruit and vegetable waste with $33 \%$ higher energy yield compared to two-stage system. The lower energy yield in the two-stage system was attributed to energy and COD loss in the hydrolysis reactor [5].

Most reported two-stage $\mathrm{AD}$ systems were operated under mesophilic temperatures. Various digester configurations (CSTR, upflow anaerobic sludge blanket (UASB) and upflow sludge bed) were adopted [2, 4, 7], 
with diversified types of feed, including: a combination of food waste and fruit and vegetable waste [17], synthetic substrate [18], high cellulosic substrate [19], a combination of swine manure and market bio-waste [16], corn stalk [20], Food waste [5, 21] as well as municipal waste with and without hydrothermal pretreatment [22]. Also, two-stage systems with thermophilic methanogenic phase [23] or thermophilic acidogenic phase [24] and temperature phased stages [25] have been examined. Recently, Micolucci et al. [26] compared the performance of single- and double-stage thermophilic reactors treating food waste, under steady-state and transient conditions. The results showed higher biogas generation $\left(0.88 \mathrm{~m}^{3} / \mathrm{kg} \mathrm{VS}\right)$ in the double-stage system compared to the singlestage digester (to $0.75 \mathrm{~m}^{3} / \mathrm{kg} \mathrm{VS}$ ), as well as $17 \%$ higher removal efficiency. Despite the extensive literature comparing one- and two-stage anaerobic digestion, comparisons during the startup phase of systems fed with SS-OFMSW, under thermophilic temperatures, are limited to non-existent. Given the importance of the start-up phase [3] and the inconsistency regarding the effectiveness of the two-stage design, this work targets a comparative analysis of the single-stage versus the two-stage design treating SS-OFMSW under thermophilic conditions during the startup of a CSTR. The assessment contrasts the performance (in terms of biogas and methane generation), treatment efficiency (organic solid reduction) and stability (alkalinity and VFA) of both systems.

77

\section{Materials and Methods}

\section{$79 \quad$ Feed preparation and characteristics}

80 The waste was collected over two weeks from 10 households to ensure a varied and representative sample. The

81 feed was ground, mixed, homogenized and stored in $150 \mathrm{ml}$ cups at $-20^{\circ} \mathrm{C}$. Prior to use, the samples were thawed 82 and diluted with distilled water to reach the required volume. The purpose of early collection and storage of waste 83 samples is to reduce fluctuations in substrate composition. The average feed's characteristics, with negligible 84 variation, are presented in Table 1 and are comparable to literature reported values with COD $=292,000 \mathrm{mg} / \mathrm{l}$ 85 [11]; total solids $(\mathrm{TS})=22.61 \%$ and $\mathrm{C} / \mathrm{N}=11.5[21]$. 
87 Table 1 Physico-chemical characteristics of SS-OFMSW

\section{Parameter}

TS (\%)

Volatile solids (VS, \%)

VS (\%TS)

Total COD (TCOD), mg/L

Soluble COD (SCOD), $\mathrm{mg} / \mathrm{L}$

Ammonia-N, mg/L

Partial Alkalinity, mg of $\mathrm{CaCO}_{3} / \mathrm{L}$

$\begin{array}{ll}\text { Average Value } & \text { Literature reported Values } \\ 21+0.2 & 18.6-52.5[21,37,39,40] \\ 20+0.2 & 32-96[37,39] \\ 95+0.2 & 60-97[37,39,40] \\ 389,172 & 292,000-630,000[11,40] \\ 13,540 & 10,400-119,000[39,40] \\ 30 & 18[40] \\ 0 & 0[40]\end{array}$

88

89

90

91

92

93

94

95

96

97

98

99

100

101

102

103

104

105

106

107

108

109

\section{Experimental procedures}

The single-stage digestion was carried out in a bench-scale digester $(9 \mathrm{~L}$ working volume, Bioflo 110, New Brunswick Scientific Co.) and the two-stage digestion was conducted in two digesters connected in series: B1 and B2 (9 L in total, 4.5 L working volume each, Anaerobic Digester W8, Armfield Ltd.) (Fig. 1). Both systems were inoculated with digestate collected from a stable single-stage digester operating at similar conditions (fed with SS-OFMSW at $\left.55^{\circ} \mathrm{C}\right)$ and running at an organic loading rate $(\mathrm{OLR})=2 \mathrm{~g} \mathrm{VS} \cdot \mathrm{L}^{-1} \cdot \mathrm{d}^{-1}$ for over a year. A similar approach of seeding single- and two-stage systems with digestate from the same single-stage digester was reported [6]. All three digesters were inoculated with $50 \%$ of their working volume $(4.5 \mathrm{~L}$ in digester A and $2.25 \mathrm{~L}$ in digesters B1 and B2, respectively). After seeding, distilled water was added to all digesters till the final working volume was reached. The $\mathrm{pH}$ of digester $\mathrm{B} 1$ was adjusted on day 1 to be between 5 and 6 with $\mathrm{HCl}(5 \mathrm{M})$, whereas digester A and $\mathrm{B} 2$ had the desired $\mathrm{pH}$ 7. The digesters were not fed until the third day after seeding. Physicochemical parameters and gas monitoring started on day 16 after inoculation.

During the first 30 days, all digesters started at low loading rates of $0.3-0.5 \mathrm{~g} \mathrm{VS} . \mathrm{L}^{-1} \cdot \mathrm{d}^{-1}$. The weight of the waste fed to the digesters was progressively increased to about $110 \mathrm{~g}$ to both systems (single- and two-stage), with the same total digester volume of 9L for A, and for B1 and B2 combined (4.5 L each). Around day 90, the OLR reached $2.0 \mathrm{~g} \mathrm{VS} . \mathrm{L}^{-1} \cdot \mathrm{d}^{-1}$ in digester A $(\mathrm{HRT}=30$ days) and maintained steady till the end of the experiment. Simultaneously, the OLR in B1 was raised to $4.2 \mathrm{~g} \mathrm{VS} \cdot \mathrm{L}^{-1} \cdot \mathrm{d}^{-1}$ (HRT 10 days). Only a portion of B1 digestate was fed into B2 digester to achieve an OLR $\left(2.4 \mathrm{~g} \mathrm{VS} \cdot \mathrm{L}^{-1} \cdot \mathrm{d}^{-1}\right)$ close to that of the single-stage digester, while maintaining an HRT of 17 days. Accordingly, the operational conditions were maintained closely similar in the one-stage and two-stage systems: $\mathrm{OLR}=2.0$ and $2.4 \mathrm{~g} \mathrm{VS} . \mathrm{L}^{-1} \cdot \mathrm{d}^{-1}, \mathrm{HRT}=30$ and 27 days, respectively. The startup period was divided into three consecutive durations according to the loading pattern and rate: Run 1 (Steady low rate), Run 2 (Incremental rate), and Run 3 (Steady high rate). 


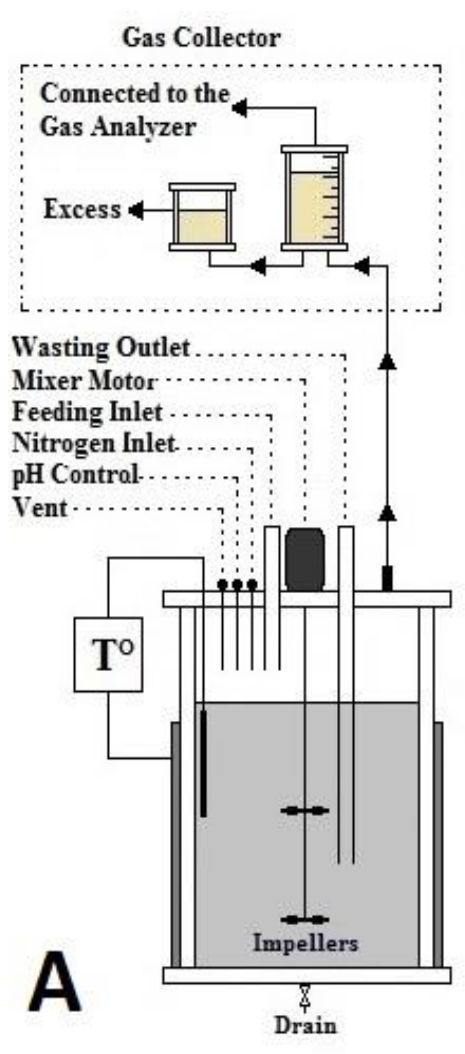

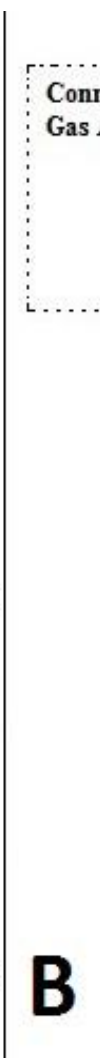

Gas Collector No 1
Gas Collector No 2

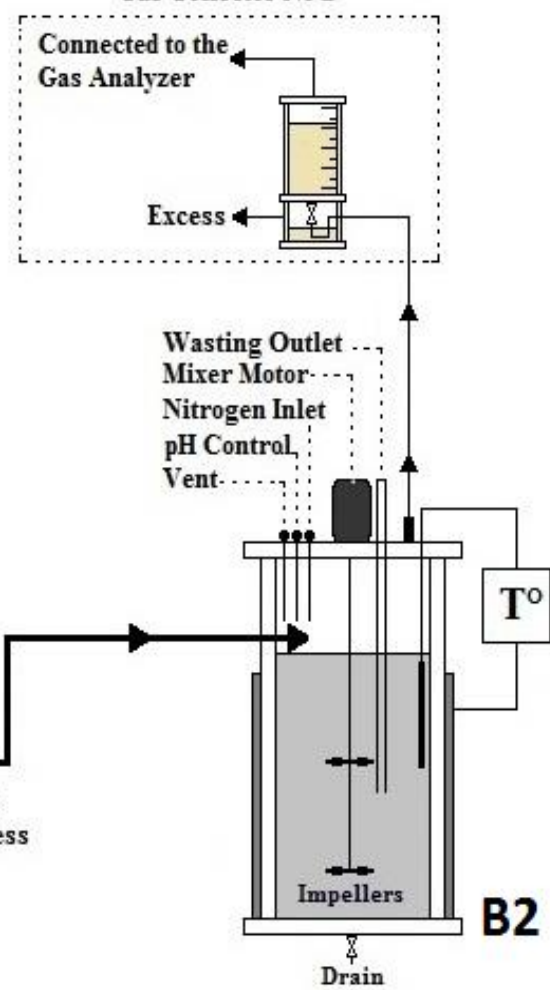

Fig. 1 Experimental Layout: (A) single-stage system; (B) two-stage system with $\mathrm{B} 1=$ acidogenic reactor and $\mathrm{B} 2=$ methanogenic reactor

Monitoring

115 The temperature of the digesters was maintained at $55 \pm 1^{\circ} \mathrm{C}$ and monitored using thermostatically controlled 116 electric heating jackets connected to built-in temperature probes. The $\mathrm{pH}$ was monitored with an immersed probe 117 and adjusted through a manually operated peristaltic pump connected to a $\mathrm{NaOH}(5 \mathrm{~N})$ solution or a $\mathrm{HCl}(5 \mathrm{~N})$ 118 solution depending on the reactor. The biogas composition (methane and carbon dioxide) was monitored once or twice per day using a dual wavelength infrared cell with reference channels (GEM-2000 monitor, Keison Products, UK). Knowing that the startup of digesters seeded with non-acclimated innocula is often unstable, hydrogen accumulation is expected [3]. Yet, given its relatively low proportion compared to $\mathrm{CH}_{4}$ and $\mathrm{CO}_{2}$, hydrogen was not monitored in this study.

123 Physico-chemical parameters were monitored on a weekly basis with samples collected from discarded digestate

124 prior to feeding. A portion of the sample was centrifuged at $13000 \mathrm{rpm}$ for $20-40$ minutes depending on the quality of the sample using a Thermo Scientific Sorvall ST16 Centrifuge and then filtered using Whatman microfiber filter $47 \mathrm{~mm}$ (pore size: $1.5 \mu \mathrm{m}$ ), the filtered portion constituted the soluble fraction. SCOD and TCOD analyses were carried out using the modification of Standard Methods 5220D procedure [36] through photometric measurements using COD Digestion Vials, High Range Plus, 0 to 15,000 mg/L. Total, dissolved and volatile 
solids (TS, VS, TDS and VDS) were determined using Standard Methods for the analysis of water and wastewater

130 [30]. Suspended solids were calculated by subtracting the volatile part of the total solids. Ammonia content was

131 determined by spectrophotometry using High Range Ammonia Nitrogen by the AmVer ${ }^{\mathrm{TM}}$ Salicylate Test 'N

132 Tube ${ }^{\mathrm{TM}}$ Method. Both COD and ammonia testing were conducted using a HACH DR/2010 Spectrophotometer.

133 Total and partial alkalinity were determined by titration with $\mathrm{HCl}(0.2 \mathrm{~N})$ to $\mathrm{pH} 4.3$ and 5.75 , respectively using

134 a Thermo Scientific Orion 3 STAR benchtop $\mathrm{pH}$, whereas the intermediate alkalinity was calculated as the

135 difference between the two parameters.

136

\section{Results and Discussion}

\section{Biogas Composition}

139 In the single-stage digester (A), methane content was constant at $33 \pm 1 \%$ during the first run (i.e. Run 1),

140 decreasing from $32 \%$ to $19 \%$ during the second week of run 2 which was paralleled by an increase in the carbon-

141 dioxide-to-methane $\left(\mathrm{CO}_{2} / \mathrm{CH}_{4}\right)$ ratio indicating methanogenic distress (Fig. 2a). This can be attributed to the OLR

142 increase during the start of run 2 which could have caused an initial shock to the methanogenic community. The

$143 \mathrm{CO}_{2} / \mathrm{CH}_{4}$ ratio kept increasing throughout the rest of the experiment to reach an average of 0.6 during run 3.

144 In comparison, $\mathrm{CO}_{2} / \mathrm{CH}_{4}$ ratio in $\mathrm{B} 2$ (the methanogenic phase of the two-stage system) started at high levels of

1450.50 and dropped to about 0.25 by the end of the experiment indicating a healthy methanogenic activity at higher

146 loading rates (Fig. 2b), evident by the high methane content ranging between 54 and $62 \%$ (and reaching $70 \%$ on

147 some days).

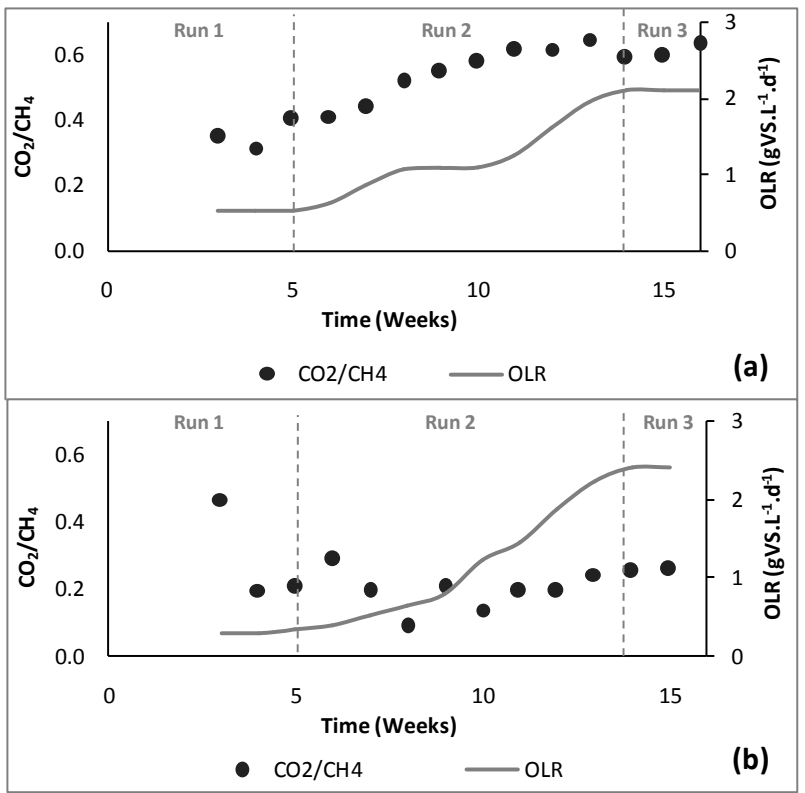

Fig. 2 Loading rate and $\mathrm{CO}_{2}$-to- $\mathrm{CH}_{4}$ ratio: (a) Digester A; (b) Digester B2*

${ }^{*}$ The $\mathrm{CO}_{2} / \mathrm{CH}_{4}$ was based on combined biogas generated from $\mathrm{B} 1$ and $\mathrm{B} 2$ 


\section{Alkalinity and pH}

153 As a process indicator, $\mathrm{pH}$ is dependent on the concentration of free VFA and the overall alkalinity of the reactor [27]. The intermediate-to-partial alkalinity (IA/PA) ratio is important as a representation of VFA alkalinity [28]; therefore, its increase is an indication of a surge in free VFA and thus a distress in the biochemical pathway. The average IA/PA ratio in $\mathrm{A}$ and $\mathrm{B} 2$ was below 0.3 , the recommended threshold for such digesters when total alkalinity is between 4000 and $8000 \mathrm{mg} \mathrm{CaCO} 3 \cdot \mathrm{L}^{-1}$ [29]. Despite starting off at a high IA/PA of 0.6, the IA/PA ratio in reactor A gradually decreased to below 0.2 by the start of run 2 and remained so during this run (Fig. 3a). Digester B2 produced an initial IA/PA ratio that was even higher than digester A, and persisted until week 5 (Fig. 3b). This could have inhibited the methanogenic community leading to the high $\mathrm{CO}_{2} / \mathrm{CH}_{4}$ ratio observed in $\mathrm{B} 2$ (Fig. 2b). Beyond week 5, the IA/PA ratio in B2 decreased gradually to as low as 0.1.

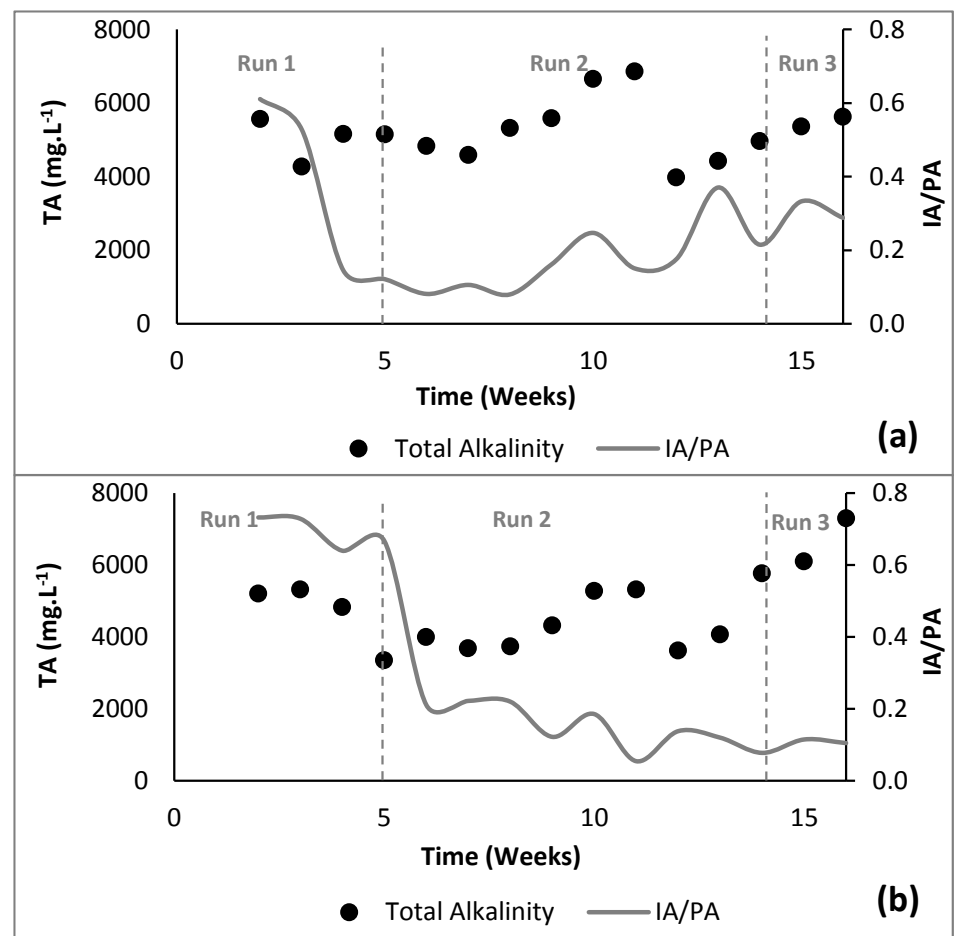

Fig. 3 Alkalinity concentrations and IA/PA ratio for digesters A (a) and B2 (b)

The $\mathrm{pH}$ in digesters A and B2, was not affected by the initial high concentration of VFA in both systems due to temporary compensation by the high buffering capacity presented by the total alkalinity (TA). The $\mathrm{pH}$ range in both digesters remained high throughout the experiment, varying within the acceptable range of 7.4 and 7.9 [9] and eliminating the need for $\mathrm{pH}$ control. The TA was relatively stable and remained above 4000 and $3500 \mathrm{mg}$ $\mathrm{CaCO}_{3} \cdot \mathrm{L}^{-1}$ for digesters A and B2, respectively - an acceptable limit according to Ganesh et al. [5]. However, 
$\left.170 \mathrm{CaCO}_{3} \cdot \mathrm{L}^{-1}\right)$ in digester B2, between weeks 11 and 12, when the OLR was increased by 26\%. This was followed

171 by a doubling in the IA/PA ratio (from 0.15 to 0.37 in A and from 0.05 to 0.12 in B2), indicating a system's upset

172 due to increased substrate loading. Nevertheless, this shock subsided quickly and the reactors recovered with an

173 average IA/PA ratio of $0.28 \pm 0.05$ and $0.10 \pm 0.02$, and an average TA of $5320 \pm 273 \mathrm{mg}$ and $5809 \pm 563 \mathrm{mg}$ of

$174 \mathrm{CaCO}_{3} \cdot \mathrm{L}^{-1}$ in digesters $\mathrm{A}$ and $\mathrm{B} 2$, respectively.

175

176 Digestate characteristics

177 Upon increasing the OLR at the start of run 2, ammonia concentrations in digester A spiked from 0.6 to 1.0 g.L ${ }^{-1}$

178 on week 7 , then decreased in week 8 , only to slowly increase again till reaching an average of 1.2 g.L $L^{-1}$ during run

1793 (Fig. 4a) - slightly higher than the reported inhibition threshold of 1.0 g.L.-1 for a similar waste type and process

180 design [30]. In comparison, ammonia levels in digester B2 remained above the 1.0 g.L.1 threshold until week 9 of

181 run 2, when they dropped to a reasonable level of 0.2 g.L.

182 of intermediate metabolites resulting in an increase in TA (3740 to $\left.5282 \mathrm{mg} \mathrm{CaCO}_{3} \cdot \mathrm{L}^{-1}\right)$ [8]. The drop in ammonia

183 was followed by a subsequent gradual increase which paralleled the increase in OLR, to a final value of $0.7 \mathrm{~g} . \mathrm{L}^{-1}$

184 during the last week.

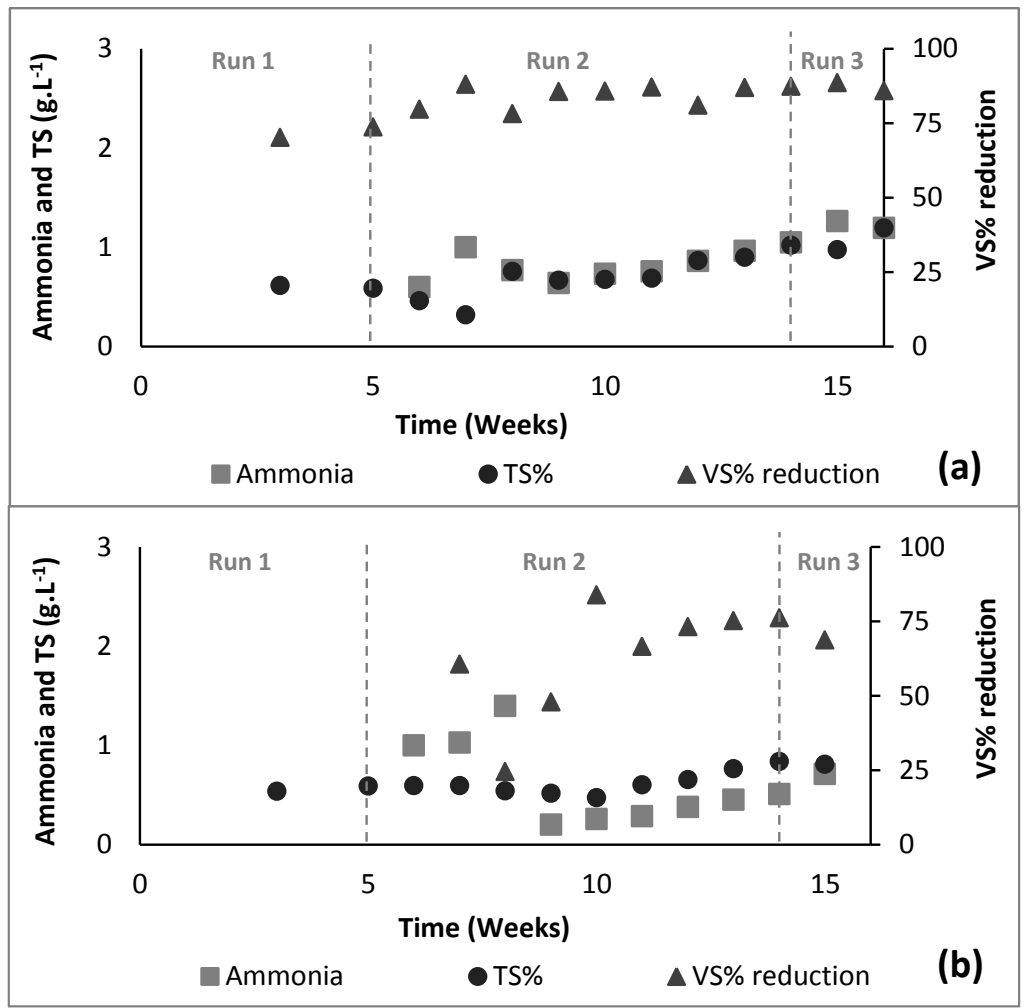

Fig. 4 Ammonia concentrations, TS of the liquor and VS removal in digester A (a) and B (b) 
187 The average TCOD and SCOD concentrations in reactor A effluent were about 10.5 g.L (1 $^{-1}$ (1.9 g.L - $^{-1}$ during Run

188 3) and 4.2 g.L.-1 (5.7 g.L L $^{-1}$ during Run 3), respectively, which are consistent with reported values [7] and indicate

189 proper use of the hydrolytic products by methanogens. In comparison, the results of digester B2, during run 3, 190 were even lower with an average TCOD and SCOD of 5.1 g.L $\mathrm{L}^{-1}$ and 1.2 g.L $\mathrm{L}^{-1}$, respectively, indicating a better 191 degradation of organic components. Similarly, total and suspended solids were lower in B2, with TS $=1.02 \%$ in 192 A vs. $0.81 \%$ in B2; and TSS $=0.52 \%$ in A vs. $0.14 \%$ in B2 (Fig. 5). The lower removal rates in digester A during 193 run 3 can be explained by the rise in ammonia levels during this run coupled with the high alkalinity of the system 194 which could hinder bacterial functions at the end of the startup [32]. Similarly, both systems underwent good 195 degradation of organic matter and resulted in a high removal of VS. During the last week of the experiment, VS removal reached $92 \%$ in the two-stage system and $86 \%$ in the single-stage system, both comparable to reported

197 results (88\% in Ward et al. [31]; 83\% in Verrier et al. [32]).

198 The concentration of the organic substrate in B1 liquor was the highest of all three digesters $(\mathrm{TS} \%=1.09 \%$, VS\% $199=0.7 \%$, TSS $=0.43 \%$, TCOD $=21.2$ g.L $\left.\mathrm{L}^{-1}\right)$ with SCOD reaching three folds of the single-stage system $(12.6$ g.L

$200{ }^{1}$ compared to 4.2 g. $\mathrm{L}^{-1}$ in A). This can be attributed to the high activity of fermenters and the absence of 201 methanogenic activity to utilize hydrolyzed products. Whereas the organic substrate in reactor B2 was the lowest among all three digesters $\left(\mathrm{TCOD}=5 \mathrm{~g} . \mathrm{L}^{-1}, \mathrm{SCOD}=1.5 \mathrm{~g} . \mathrm{L}^{-1}, \mathrm{TSS}=0.13 \%, \mathrm{TS}=0.64 \%, \mathrm{VS}=0.29 \%\right)$ arguably

203 because most of the hydrolysis and degradation of larger polymers was achieved in the first stage, and acetate is consumed by methanogens in the second stage [5] (Fig. 5). It is worth noting that prior to the decrease in ammonia concentration during week 9, the VS reduction in the B2 effluent was low, averaging at $43 \%$, and improved significantly to an average of $90 \%$ afterwards, exceeding the results of digester A. This is expected in two-stage digesters, where organic matter degradation is superior than in single-stage digesters, due to fermenters thriving in optimal acidic environments [6]. 


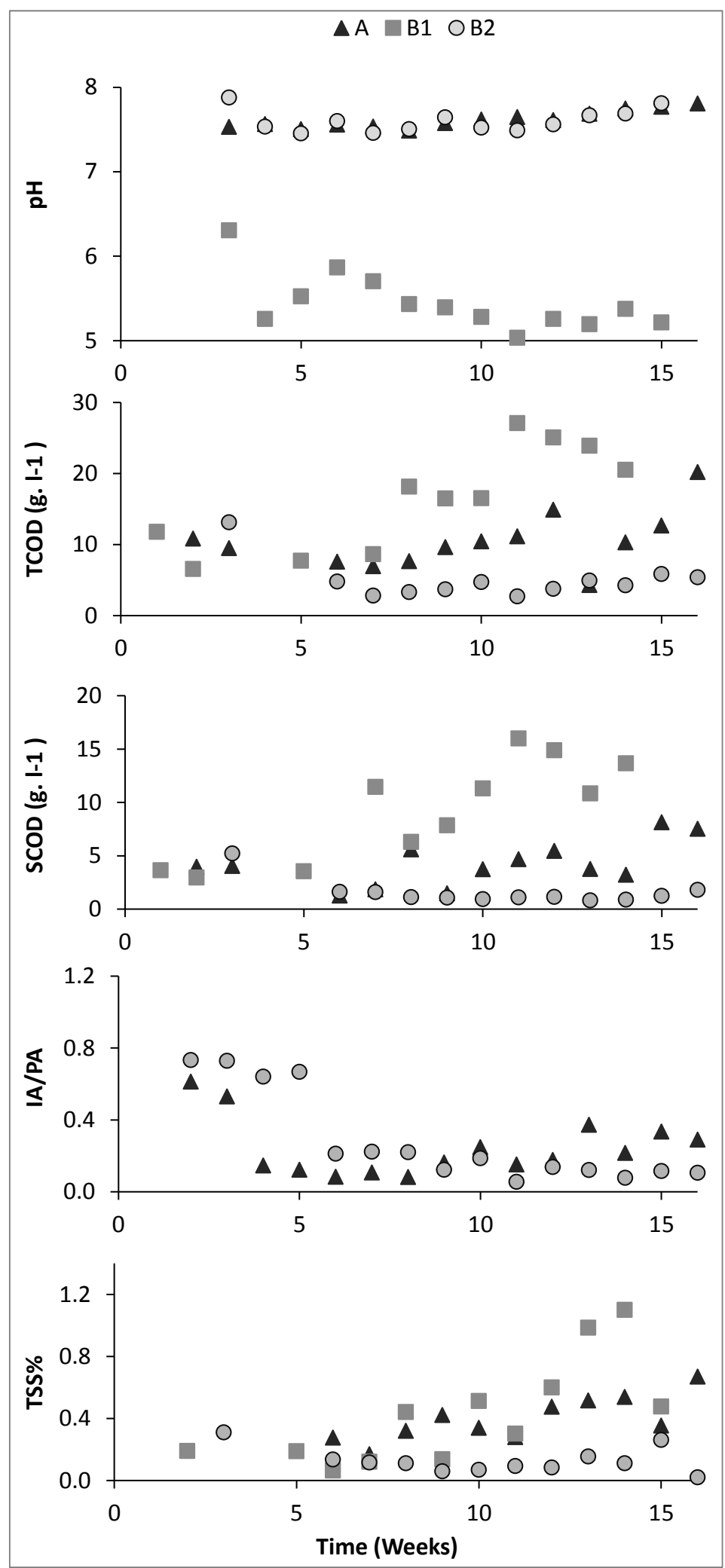

Fig. 5 Effluent characteristics for digesters A, B1 and B2 


\section{Impact of stage separation}

216 Considering the difference in $\mathrm{pH}$ and operational parameters imposed in the two-stage compartments, a difference

217 in the composition, abundance and activity of some microbial communities of B1 and B2 is expected [33]. This

218 is likely to lead to a superior hydrolysis and better destruction of organic matter due to ideal acidic conditions

219 provided to the hydrolytic and acidogenic communities [6]. In fact, the final percentage of total and suspended

220 solids in the two-stage effluent was lower than the single-stage system (Fig. 5). Similarly, the removal of TCOD

221 and SCOD was 52\% and 64\%, respectively, higher than the single-stage system. These findings are consistent

222 with those reported by Liu et al. [34], Massanet-Nicolau et al. [35], Micolucci et al. [26], and Nasr et al. [6] but

223 inconsistent with the findings of Nair et al. [18] where the lower organic matter degradation in two-stage digesters

224 was attributed to a decrease in the protozoan population. Also, the results do not concur with those of Shen et al.

225 [17] and Park et al. [9] who reported insignificant differences in COD removal between both systems.

226 During the early stages, methane concentration in the two-stage system was low, possibly because the starting

227 loading rate was low and the seed (retrieved from a single-stage digester) was not originally acclimated to the conditions in the methanogenic digester (B2). Yet, upon reaching steady loading in Run 3, the overall methane

229 concentration in the total biogas produced from the two-stage system became constantly higher (Fig. 6). Thus, it can be concluded that separating the digestion phases in the two-stage system and increasing the distance between syntrophic bacteria did not hinder methanogenesis $[13,14,15,16]$. Also, the abundance of hydrolyzed substrates and easily fermentable organic matter, transferred from the acidogenic reactor, does not seem to cause a serious shock to the methane producing community in the methanogenic reactor [16]. This agrees with the findings of $\mathrm{Li}$ et al. [20] whereby the two-phase mesophilic digesters exhibited a better performance, compared to single-stage digesters, in treating hydrothermally pretreated MSW. Yet, the observations in this study contradict the findings of Massanet-Nicolau et al. [35] and Shen et al. [17] who reported better performance in single-stage systems treating wheat feed pellets and food waste, respectively, under mesophilic conditions and Schievano et al. [16] reporting practically similar performance in energy generation of the two systems. 


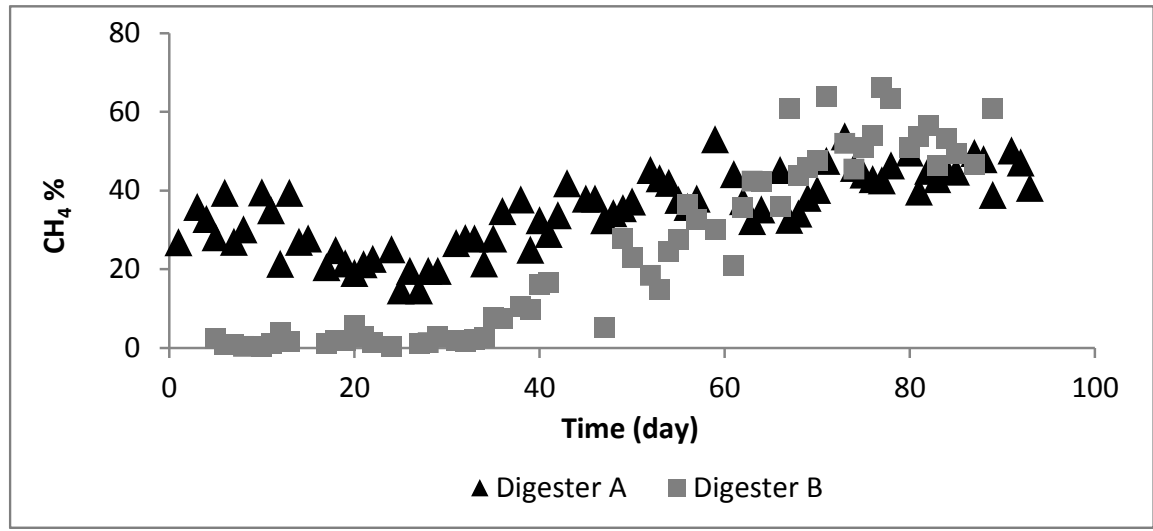

Fig. 6 Daily $\mathrm{CH}_{4}$ content: (a) Digester A; (b) Digester B* ${ }^{*}$ Considering combined biogas generated from $\mathrm{B} 1$ and $\mathrm{B} 2$

\section{Conclusion}

244 Single- and two-stage anaerobic digestion of SS-OFMSW were compared during thermophilic start-up at OLR $\leq$

$2452 \mathrm{gVS} \cdot \mathrm{l}^{-1} \cdot \mathrm{d}^{-1}$. The digesters were monitored for biogas composition, COD removal, IA/PA ratio and ammonia 246 concentration. The superior performance of the two-stage system treating SS-OFMSW, at thermophilic 247 temperatures, was demonstrated with: (a) better effluent quality, with $79 \%$ and $57 \%$ lower average TCOD and 248 SCOD, respectively, and (b) higher methane content of 54\%, compared to $45 \%$ in single-stage digestion, upon reaching steady feeding.

Acknowledgments This research was supported by a grant from the National Council for Scientific Research,

252 Lebanon. Special thanks are extended to the United States Agency for International Development for its support in acquiring the equipment used in the experimental program.

\section{References}

256 1. Van Fan, Y., Klemeš, J. J., Lee, C. T., Perry, S.: Anaerobic digestion of municipal solid waste: energy and 257 carbon emission footprint. J Environ Manage, 223, 888-897 (2018).

258 2. Handous, N., Gannoun, H., Hamdi, M., Bouallagui, H.: Two-stage anaerobic digestion of meat processing 259 solid wastes: methane potential improvement with wastewater addition and solid substrate 260 fermentation. Waste Biomass Valori, 1-12 (2017).

261 3. El-Fadel, M., Saikaly, P., Ghanimeh, S.: Startup and stability of thermophilic anaerobic digestion of OFMSW. Crit Rev Env Sci Tec, 43(24), 2685-2721 (2013). 
263 4. Fuess, L. T., Klein, B. C., Chagas, M. F., Rezende, M. C. A. F., Garcia, M. L., Bonomi, A., \& Zaiat, M.: 264 Diversifying the technological strategies for recovering bioenergy from the two-phase anaerobic digestion of 265 sugarcane vinasse: An integrated techno-economic and environmental approach. Renew Energ, 122, 674-687 266 (2018).

267 5. Ganesh, R., Torrijos, M., Sousbie, P., Lugardon, A., Steyer, J.P., Delgenes, J.P.: Single-phase and two-phase 268 anaerobic digestion of fruit and vegetable waste: Comparison of start-up, reactor stability and process performance. Waste Manage, 34, 875-885 (2014).

270 6. Nasr, N., Elbeshbishy, E., Hafez, H., Nakhla, G., Hesham, El Naggar, M.: Comparative assessment of single271 stage and two-stage anaerobic digestion for the treatment of thin stillage. Bioresour Technol, 111, 122-126 272 (2012).

273 7. Ali, A., Hashmi, N., Ehsanullah, Khan, K.A., Iqbal, J., Nosheen, G.: Performance evaluation of the two-stage 274 uasb reactor using methanolic wastes. Electron. J Environ Agric Food Chem, 10, 2735-2743 (2011).

275 8. Vandevivere, P., De Baere, L., Verstraete, W.: Types of anaerobic digester for solid wastes, in: Mata-Álvarez. 276 J. (Ed.), Biomethanization of the organic fraction of municipal solid wastes. IWA publishing, UK, pp. 111 277 (2003).

278 9. Park, Y., Hong, F., Cheon, J., Hidaka, T., Tsuno, H.: Comparison of thermophilic anaerobic digestion 279 characteristics between single-phase and two-phase systems for kitchen garbage treatment. J. of Biosci Bioeng, 105(1), 48-54 (2008).

281 10. Martín-Pascual, J., Rueda-Pérez, J.J., Jóver, M., Hontoria, E., Poyatos, J.M.: Optimization of the Acid Stage 282 of a Two-Stage Anaerobic Digestion Process to Treat Urban Wastewater Sludge. J Environ Eng, 143(9) 283 (2017).

284 11. Bolzonella, D., Innocenti, L., Pavan, P., Traverso, P., Cecchi, F.: Semi-dry thermophilic anaerobic digestion 285 of the organic fraction of municipal solid waste: Focusing on the start-up phase. Bioresour Technol, 86, 123$286129(2003)$

287 12. Forster-Carneiro, T., Perez, M., Romero, L.I.: Anaerobic digestion of municipal solid wastes: Dry thermophilic performance. Bioresour Technol, 99, 8180-8184 (2008). 
289 13. Qin, Y., Li, L., Wu, J., Xiao, B., Hojo, T., Kubota, K., Li, Y. Y.: Co-production of biohydrogen and 290 biomethane from food waste and paper waste via recirculated two-phase anaerobic digestion process: 291 Bioenergy yields and metabolic distribution. Bioresource Technol, 276, 325-334 (2019).

292 14. Blonskaja, V., Menert, A., Vilu, R.: Use of two-stage anaerobic treatment for distillery waste. Adv Environ 293 Res, 7, 671-678 (2003).

294 15. Reith, J.H., Wijffels, R.H., Barten, H.: Bio-methane and bio-hydrogen, Status and perspectives of biological 295 methane and hydrogen production. Dutch Biological Hydrogen Foundation, The Netherlands (2003).

296 16. Schievano, A., Tenca, A., Lonati, S., Manzini, E., Adani, F.: Can two-stage instead of one-stage anaerobic 297 digestion really increase energy recovery from biomass?. Applied Energ, 124, 335-342 (2014).

298 17. Shen, F., Yuan, H., Pang, Y., Chen, S., Zhu, B., Zou, D.: Performances of anaerobic co-digestion of fruit \& 299 $300 \quad$ (2013).

301 18. Nair, S., Kuang, Y., Pullammanappallil, P.: Enhanced degradation of waste grass clippings in one and two 302 stage anaerobic systems. Environ Technol, 26, 1003-1012 (2005).

303 19. Meng, Y., Jost, C., Mumme, J., Wang, K., Linke, B.: An analysis of single and two stage, mesophilic and 304 thermophilic high rate systems for anaerobic digestion of corn stalk. Chem Eng J., 288, 79-86 (2016).

305 20. Li, W., Loh, K. C., Zhang, J., Tong, Y. W., \& Dai, Y.: Two-stage anaerobic digestion of food waste and 306 horticultural waste in high-solid system. Appl Energ, 209, 400-408 (2018).

307 21. Ariunbaatar, J., Di Perta, E. S., Panico, A., Frunzo, L., Esposito, G., Lens, P. N., Pirozzi, F.: Effect of 308 ammoniacal nitrogen on one-stage and two-stage anaerobic digestion of food waste. Waste Manage, 38, 388398 (2015).

310 22. Trisakti, B., Irvan, M., Taslim, Turmuzi, M.: Effect of temperature on methanogenesis stage of two-stage 311 anaerobic digestion of palm oil mill effluent (POME) into biogas. IOP Conference Series: Mater Sci Eng, 206(1) (2017).

313 23. Ventura, J.R. S., Lee, J., Jahng, D. A.: comparative study on the alternating mesophilic and thermophilic twostage anaerobic digestion of food waste. J Environ Sci, 26, 1274-1283 (2014). 
315 24. Rubio-Loza, L. A., Noyola, A.: (2010). Two-phase (acidogenic-methanogenic) anaerobic 316 thermophilic/mesophilic digestion system for producing Class A biosolids from municipal sludge. Bioresour 317 Technol, 101(2), 576-585 (2010).

318 25. Nielsen, H.B., Mladenovska, Z., Westermann, P., Ahring, B.K.: Comparison of two-stage thermophilic (68 $\left.319 \mathrm{C} / 55^{\circ} \mathrm{C}\right)$ anaerobic digestion with one-stage thermophilic $\left(55^{\circ} \mathrm{C}\right)$ digestion of cattle manure. Biotechnol 320 Bioeng, 86, 291-300 (2004).

321 26. Micolucci, F., Gottardo, M., Pavan, P., Cavinato, C., Bolzonella, D.: Pilot scale comparison of single and double-stage thermophilic anaerobic digestion of food waste. J Clean Prod, 171, 1376-1385 (2018).

323 27. Björnsson, L., Murto, M., Jantsch, T.G., Mattiasson, B.: Evaluation of new methods for the monitoring of 324 alkalinity, dissolved hydrogen and the microbial community in anaerobic digestion. Water Res, 35, 2833-2840 $325 \quad$ (2001).

326 28. Banks, C.J., Chesshire, M., Heaven, S., Arnold, R.: Anaerobic digestion of source-segregated domestic food 327 waste: Performance assessment by mass and energy balance. Bioresour Technol, 102, 612-620 (2011).

328 29. Martín-González, L., Font, X., Vicent, T.: Alkalinity ratios to identify process imbalances in anaerobic 329 digesters treating source-sorted organic fraction of municipal wastes. Biochem Eng J, 76, 1-5 (2013).

330 30. Yenigün, O., Demirel, B.: Ammonia inhibition in anaerobic digestion: A review. Process Biochem, 48, 901331 $911(2008)$.

332 31. Ward, A.J., Hobbs, P.J., Holliman, P.J., Jones, D.L.: Optimisation of the anaerobic digestion of agricultural 333 resources. Bioresour Technol, 99, 7928-7940 (2008).

334 32. Verrier, D., Roy, F., Albagnac, G.: Two-phase methanization of solid vegetable wastes. Biol Wastes 22, 163335 177 (1987).

336 33. Zhang, T.C., Noike, T.: Comparison of one-phase and two-phase anaerobic digestion processes in characteristics of substrate degradation and bacterial population levels. Water Sci. Technol. 23, 1157-1166 (1991).

339 34. Liu, D., Liu, D., Zeng, R.J.: Angelidaki, I. Hydrogen and methane production from household solid waste in the two-stage fermentation process. Water Res, 40, 2230-2236 (2006). 
341 35. Massanet-Nicolau, J., Dinsdale, R., Guwy, A., Shipley, G.: Use of real time gas production data for more 342 accurate comparison of continuous single-stage and two-stage fermentation. Bioresour Technol, 129, 561-567 $343 \quad$ (2013).

344 36. Conklin, A.S., Chapman, T., Zahler, J.D., Stensel, H.D., Ferguson, J.F.: Monitoring the role of aceticlasts in 345 anaerobic digestion: Activity and capacity. Water Research, 42, 4895-4904 (2008).

346 37. Li, Y., Liu, H., Su, D. and Yan, F.: Characterization and Thermophilic Anaerobic Digestion of Organic 347 Fraction of Municipal Solid Waste, Waste Biomass Valori, 7, 325-330 (2016).

348 38. Garcia-Garcia, G., Woolley, E., Rahimifard, S., Colwill, J., White, R. and Needham, L.: A Methodology for 349 Sustainable Management of Food Waste, Waste Biomass Valori, 8, 2209-2227 (2017).

350 39. Ghanimeh, S., El-Fadel, M. and Saikaly, P.: Mixing effect on thermophilic anaerobic digestion of source351 sorted organic fraction of municipal solid waste, Bioresour Technol, 117, 63-71 (2017).

352 40. Ghanimeh, S., El-Fadel, M. and Saikaly, P.: Improving the stability of thermophilic anaerobic digesters 353 treating SS-OFMSW through enrichment with compost and leachate seeds, Bioresour Technol, 131, 53-59 (2013). 